\title{
Investigations into the Biocompatibility of Nanohydroxyapatite Coated Magnetic Nanoparticles under Magnetic Situation
}

\author{
Qing Li, ${ }^{1,2}$ Gang Zhou, ${ }^{1}$ Tong Wang, ${ }^{2}$ Yongzhao Hou, ${ }^{1}$ Xuliang Deng, ${ }^{3}$ and Yan Wei ${ }^{3}$ \\ ${ }^{1}$ Key Laboratory for Biomechanics and Mechanobiology of Ministry of Education, School of Biological Science and Medical Engineering, \\ Beihang University, Beijing 100191, China \\ ${ }^{2} 2$ nd Dental Center, Peking University School and Hospital of Stomatology, Beijing 100081, China \\ ${ }^{3}$ Department of Geriatric Dentistry, Peking University School and Hospital of Stomatology, Beijing 100081, China
}

Correspondence should be addressed to Yan Wei; kqweiyan@126.com

Received 13 November 2014; Revised 30 December 2014; Accepted 30 December 2014

Academic Editor: Shuming Zhang

Copyright (C) 2015 Qing Li et al. This is an open access article distributed under the Creative Commons Attribution License, which permits unrestricted use, distribution, and reproduction in any medium, provided the original work is properly cited.

Regenerative medicine consisting of cells and materials offers a new approach for repairing and regenerating the organs and tissues. More and more researches focused on the magnetic nanobiomaterials due to its superior advantages to traditional materials. However, the toxicity of nanosized magnetic particles cannot be ignored, especially under the magnetic situation. This study aims to study the biocompatibility of nanohydroxyapatite (n-HA-) coated magnetic nanoparticles under the magnetic situation. n-HA-coated magnetic nanoparticles were fabricated through an ultrasound-assisted coprecipitation method. Subsequently, these materials were analyzed by transmission electron microscope (TEM) and X-ray diffraction (XRD) and then were cultured with mesenchyme stem cells derived from human bone marrow (hMSC-BM). In vitro experiment proved the satisfactory biocompatibility of n-HA-coated magnetic nanoparticles. These important factors (ALP, OCN, and OPN) influence the osteogenic differentiation of hMSC-BM. It was found that the hMSC-BM with combination of n- $\mathrm{HA} / \mathrm{Fe}_{3} \mathrm{O}_{4}$ and magnetic stimulation presented higher degree of osteoblast-related markers than that in each alone. This research demonstrated that a novel nanohydroxyapatite coated magnetic nanoparticle is safe under the magnetic situation. Therefore, these n-HA-coated magnetic nanoparticles are promising biomagnetic materials for future applications.

\section{Introduction}

In recent years, nanosized magnetic biomaterials have shown their bright future in the regenerative medicine [1-4]. It is well known that magnetic nanoparticles [5-7] are endowed with extensive biological effects. By virtue of their ability to interact with living cells, they can stimulate the growth and elongation of cells under the influence of external magnetic fields [8]. Specifically, the development of magnetic nanoparticles for the application in biomedical field contains both magnetic hyperthermia and medical imaging. At present, drug or gene delivery is experiencing a tremendous development [4]. As the research revealed, magnetic nanoparticles could significantly facilitate the proliferation and differentiation of MSCs (mesenchymal stem cells, MSCs) $[9,10]$. The magnetic $\mathrm{CaPO}_{4} / \mathrm{Fe}_{3} \mathrm{O}_{4}$ composite could promote new bone formation after being implanted into the subcutaneous of rats [11]. Magnet can also affect the flow of $\mathrm{Ca}^{2+}$ in cell plasma, which will directly or indirectly cause the reconstruction of microfilaments, micropipes, and surficial glycosyl and consequently impact the cell morphology and cell membrane rebuilding [12-16]. With these unique biological effects, magnetic materials were considered to possess great potentials in regenerative medicine.

Nonetheless, attributing to the physicochemical characteristics of the nanomaterial like its small shape, size, and unrecognized surface reaction, this novel material also draws far-reaching attention on its biosafety $[17,18]$. It is observed that the direct biomedical application of the nanomaterials like $\mathrm{Fe}_{3} \mathrm{O}_{4}$ is likely to cause cellular toxicity $[19,20]$. Therefore, nontoxicity is perhaps the most basic requirement for magnetic materials to be applied in biomedical field. For this 
purpose, synthesized $\mathrm{Fe}_{3} \mathrm{O}_{4}$ is generally coated with proper ligands or moieties before use so as to weaken the cellular toxicity while enhancing the biocompatibility [21, 22].

Featured with prominent bioactivity and biocompatibility, nanohydroxyapatite (n-HA) becomes a perfect candidate and thus is extensively applied in the field of tissue regeneration [23-27]. Contrasted with traditional micromaterials, n-HA can arouse a higher level of biological plasticity with its superior advantage of a high surface-to-volume ratio [28]. Thus, n-HA was added to coat magnetic nanoparticles to overcome its cytotoxic effect in the former study [29].

Electromagnetic biology mainly explores the impacts of electric and magnetic fields on the living organs. From the researches on this subject in the past dozens of years, it has been convincingly proved that through perceiving the direction of the geomagnetic field, various species like sea turtles, birds, and butterflies can navigate for a long distance, while mammalian species are able to line up on the earth $[30,31]$. Besides the impacts of the geomagnetic field on species behavior, the electromagnetic biology also explores the underlying negative impacts of diverse environmental electromagnetic fields (EMFs). The EMFs from mobile phones and power lines are representative ones daily. There are also static magnetic fields (SMF) from magnetic levitation and magnetic resonance imaging system [32]. Particularly, more and more researches have demonstrated that SMF treatments will trigger genotoxicity, apoptosis, and cellular differentiation in different types of cells [33]. Nonetheless, none of former researches has appropriately studied the impacts of magnetic nanoparticles integrated with SMF exposure on cytotoxicity. For electromagnetic biology, it makes sense to measure the cellular toxicity of magnetic nanoparticles under magnetic environment, for magnetic nanoparticles like $\mathrm{Fe}_{3} \mathrm{O}_{4}$ will be magnetized under SMF and may impose unrecognized negative impacts on living organs.

In terms of biomedical application, this novel nanostructure demands strict assessment on its biological security under the magnetic situation. Therefore, this research aimed to characterize the biocompatibility of a novel magnetic hydroxyapatite composite under the magnetic environment. Firstly, the properties of the developed n-HA-coated magnetic nanoparticles were characterized by XRD and TEM. Then, we created a novel magnetic force bioreactor which exposed a magnetic force during the cell culture. Besides, the in vitro bioactivity and biocompatibility of magnetic composite nanoparticles were investigated with the hMSC$\mathrm{BM}$ cells under this magnetic environment.

\section{Materials and Methods}

The chemical reagents applied in this research were all in analytical grade.

2.1. Synthesis of $n-H A$. Through a precipitation approach, n-HA slurry was synthesized [34]. In brief, trisodium phosphate $\left(\mathrm{Na}_{3} \mathrm{PO}_{4} \cdot 12 \mathrm{H}_{2} \mathrm{O}\right)$ (Beijing Chemical Reagents, $0.31 \mathrm{~mol} / \mathrm{L})$ solution was dropwise added to the calcium nitrate $\left(\mathrm{Ca}\left(\mathrm{NO}_{3}\right)_{2} \cdot 4 \mathrm{H}_{2} \mathrm{O}\right.$, Beijing Chemical Reagents, $95 \mathrm{wt} \%$ pure, $0.55 \mathrm{~mol} / \mathrm{L}$ ) according to a $\mathrm{Ca} / \mathrm{P}$ molar ratio of $5: 3$. During the reaction, the solution was kept stirring vigorously and the $\mathrm{pH}$ was regulated to 14 via adding a certain ammonia solution $\left(\mathrm{NH}_{4} \cdot \mathrm{OH}\right.$, Beijing Chemical Reagents) at $25^{\circ} \mathrm{C}$. Through titration and aging for one day (24 hours), the precipitates could be collected via centrifuging the suspension and washing them in the distilled water. Eventually, the HA powder could be acquired when the solution dried.

2.2. Synthesis of $n$-HA-Coated Magnetic Nanoparticles. $\mathrm{FeCl}_{3} \cdot 6 \mathrm{H}_{2} \mathrm{O}(0.55 \mathrm{~mol} / \mathrm{L}), \mathrm{FeCl}_{2} \cdot 4 \mathrm{H}_{2} \mathrm{O}(0.25 \mathrm{~mol} / \mathrm{L})$, and $\mathrm{Ca}$ $\left(\mathrm{NO}_{3}\right)_{2} \cdot 4 \mathrm{H}_{2} \mathrm{O}(0.55 \mathrm{~mol} / \mathrm{L})$ were jointly dissolved in water so as to prepare the solution [A]. Besides, $\mathrm{Na}_{3} \mathrm{PO}_{4} \cdot 12 \mathrm{H}_{2} \mathrm{O}$ $(0.3 \mathrm{~mol} / \mathrm{L})$ and $\mathrm{NH}_{3} \cdot \mathrm{H}_{2} \mathrm{O}(1.55 \mathrm{~mol} / \mathrm{L})$ were also dissolved in water to prepare solution [B]. Subsequently, the solution [B] was dropwise added to the solution [A] with ultrasoundassisted stirring. After ultrasound-assisted dispersion at $25^{\circ} \mathrm{C}$ for 5 hours, the solution was left still for aging for 24 hours at room temperature. Afterwards, the precipitates could be screened from mother liquor through centrifugation, washed in the distilled water, and then centrifuged several times. Eventually, the n-HA-coated magnetic nanoparticles powder could be collected after drying.

2.3. Characterization of Materials. The crystal structure of the synthesized materials was characterized by the X-ray diffractometry (XRD, X'Pert pro-MPD PANalytical B.V.) with $\mathrm{Cu} / \mathrm{Ka}$ radiation $(\lambda=0.15405 \mathrm{~nm})(40 \mathrm{kV}, 40 \mathrm{~mA})$. The powder morphology could be analyzed by transmission electron microscopy (TEM) which was implemented by a JEOL JEM 1200EX $(120 \mathrm{kV})$. The magnetic performance was characterized by a Vibrating Sample Magnetometer 7307 at room temperature $\left(25^{\circ} \mathrm{C}\right)$.

2.4. Cell Cultures with Magnetic Nanoparticles. Primary cultures of human mesenchymal stem cells-bone marrow (hMSC-BM, Sciencell, USA) were cultured as monolayers in Alpha Minimum Essential Medium ( $\alpha$-MEM, GIBCO), supplemented with $10 \%(\mathrm{v} / \mathrm{v})$ fetal bovine serum (FBS; Sigma), 1\% (v/v) L-glutamine (Invitrogen Corp., Carlsbad, CA, USA), and a $1 \%(\mathrm{v} / \mathrm{v})$ antibiotic and antimycotic formulation containing penicillin $\mathrm{G}$ sodium and streptomycin sulfate (Invitrogen Corp., Carlsbad, CA, USA). In addition, the medium was renewed every other day, while the cultures were kept at $37^{\circ} \mathrm{C}$ within a humid atmosphere with $5 \% \mathrm{CO}_{2}$. When the confluence reached $90 \%$, the cells were passaged (P1). After passaging three times (P3), the cells were exposed to proliferation and differentiation assays.

Fe magnetic nanoparticles were added into culture medium at $138 \mu \mathrm{g} / \mathrm{mL}$ during cell cultures. n-HA-coated magnetic nanoparticles were added into culture medium at $138 \mu \mathrm{g} / \mathrm{mL}$ during cell cultures. The cells cultured with Fe and n-HA were seeded in plates with culture medium and exposed to a magnetic force bioreactor (Figure 1) every one hour at every other day of cyclic loading intervals for a 14day period. The magnetic flux density of the central field is about $0.2 \mathrm{~T}$. 


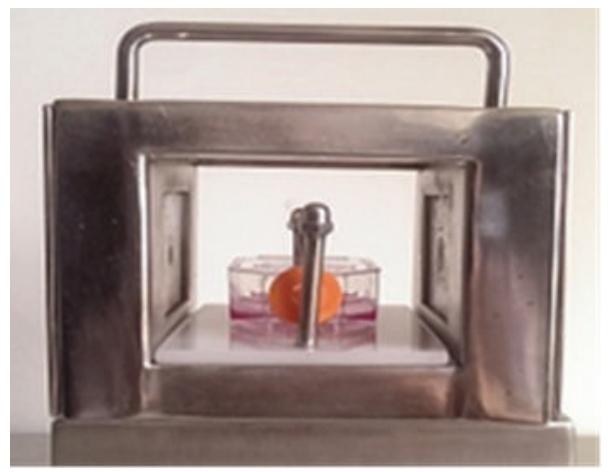

(a)

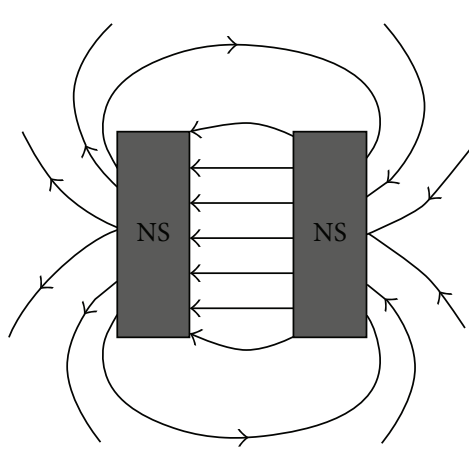

(b)

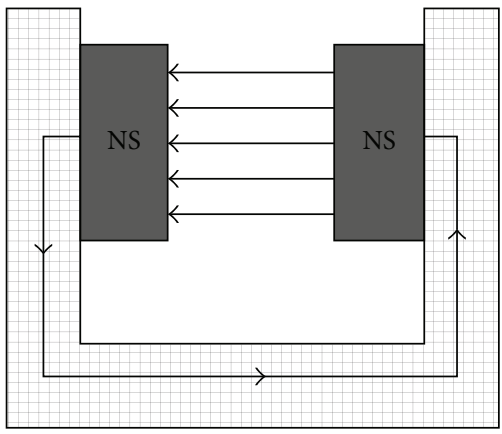

(c)

FIGURE 1: The magnetic force bioreactor and the diagram of the magnetic principle ((a) the picture of magnetic force bioreactor shows the cell culture is located in the central field; (b) the distribution of magnetic induction line when two different polarity magnets face each other; (c) the distribution of magnetic induction line when two different polarity magnets face each other with a steel case device.).

2.5. Cell Viability. The cell viability was determined by CCK8 kit (Beyotime, China). In brief, 10 ul of the kit reagent was added into the cells, then processed as the above-mentioned steps in 96-well plates, and cultured for 2 hours. In this way, the cell viability could be evaluated via the ELISA plate reader at $450 \mathrm{~nm}$. The cells were exposed to proliferation assays using CCK8 kits at 1d, 3d, 5d, 7d, and 14d.

2.6. SEM Observation. All cell suspensions $(5 \mathrm{~mL})$ were plated at the density of $1 \times 10^{6}$ cells $\mathrm{mL}^{-1}$ in plates with sterile specimens of materials for the cell attachment assays. SEM micrographs were carried out at one day following the original cell coculturing with the materials. In brief, the cocultured structures could be harvested, then washed with PBS, and lastly fixed with $4 \%$ glutaraldehyde. After 3 rinses with water, these samples could be dehydrated via a series of graded alcohol solutions and dried overnight. The specimens were observed by SEM at an acceleration voltage of $30 \mathrm{kV}$ (QUANTA 250 FEG, USA).

2.7. Immunofluorescence Assay. For the immunofluorescence observation of cytoskeleton of hMSC-BM, the cells were gently bathed with $0.01 \mathrm{M}$ PBS 3 times before being fixed with $4 \%$ glutaraldehyde PBS solution for $20 \mathrm{~min}$ at $4^{\circ} \mathrm{C}$. Afterwards, cells were rinsed with PBS and incubated with $0.5 \%$ Triton $\mathrm{X}-100$ for 5 minutes to increase cell membrane's penetrability. The cells were subsequently blocked with $1 \%$ BSA solution for
1 hour at room temperature. After removing BSA solution, the cells were incubated with rhodamine phalloidin (Cat. PHDR1) in a dark place at room temperature for half an hour. Then the samples were rinsed twice for $30 \mathrm{~s}$ with PBS and incubated in Hoechst $33258(10 \mathrm{ug} / \mathrm{mL})$ in a dark place at room temperature for $5 \mathrm{~min}$ to show the cell nucleus. Again, the samples were washed 3 times for 3 min with PBS. Finally, these samples were mounted with $95 \%$ glycerin PBS solution. Images were taken under a confocal microscope (Olympus IX71, Fluoview, Japan) with an excitation filter at $535 \mathrm{~nm}$ and an emission filter at $585 \mathrm{~nm}$ for rhodamine and an excitation filter at $550 \mathrm{~nm}$ and an emission filter at $460 \mathrm{~nm}$ for Hoechst 33258, respectively.

2.8. ALP Activity Analysis. The activity ALP derived from the cells could be decided through a dynamic colorimetric assay. hMSC-BM were cultured separately in 24-well plates containing osteogenic medium; at each time-point, the cultures were rinsed with cellular culture media and separated with $0.3 \mathrm{~m}$

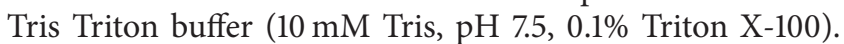
The samples then were solicited for $5 \mathrm{~min}$ at $25 \mathrm{~W}$ on a piece of ice. Subsequently, they were centrifuged at $2000 \mathrm{rpm}$ for $10 \mathrm{~min}$ and diluted ten times with the same buffer. A moiety of every supernatant was poured into p-nitrophenyl phosphate solution (Randox) at room temperature in a 96-well plate and the absorbancy of the colored product of p-nitrophenol was surveyed at $405 \mathrm{~nm}$ per min for 5 minutes using the ELISA 
TABLE 1: Chain reaction primers used for detection in this study.

\begin{tabular}{lcc}
\hline Primers sequence & $\begin{array}{c}\text { Target } \\
\text { gene }\end{array}$ & Product size (bp) \\
\hline CAGGCGCTACCTGTATCAATG & OCN & 112 \\
GTGGTCAGCCAACTCGTCA & & \\
GTGCATACAAGGCCATCC & OPN & 116 \\
GTGGGTTTCAGCACTCTGG & & \\
$\begin{array}{l}\text { TGCGCAGAAAACAAGATGAG } \\
\text { CACCTTCACCGTTCCAGTTT }\end{array}$ & ACTIN & 114 \\
\hline
\end{tabular}

plate reader. The slope of the absorbancy to time plot was utilized to measure the ALP activity. The calibration curve of p-nitrophenol at room temperature was adopted to decide the enzymatic activity in units of nmol substrate transformed into product every minute.

2.9. Western Blotting Analysis. HMSC-BM cells were lysed in a RIPA buffer with supplementation of protease inhibitors (SinoGene Scientific, Beijing, China) and phosphatase inhibitors (SinoGene Scientific, Beijing China). Protein concentration was determined by the Bradford method. $30 \mu \mathrm{g}$ protein lysate was mixed with $2 \mathrm{x}$ loading buffer at $1: 1$ and heated for $10 \mathrm{~min}$ at $95^{\circ} \mathrm{C}$ before being loaded for gel electrophoresis.

The proteins and protein marker (SM1881, Thermo Fermentas) could be separated through SDS-PAGE (4\% stacking gel and $12 \%$ separating gel) at $120 \mathrm{~V}$ for $2 \mathrm{~h}$. Proteins were then transferred into the PVDF membranes via a Bio-Rad mini transfer system. The membranes were blocked in a rapid blocking buffer for $5 \mathrm{~min}$ and then probed with primary antibodies against OCN and OPN at a dilution of 1:1000 for $2 \mathrm{~h}$. After rinsing three times with PBS for 10 minutes per rinse, HRP-conjugated anti-mouse and anti-rabbit antibodies (Micro Analysis Inc.) were applied to the membranes at a dilution of $1: 2000$ for $1 \mathrm{~h}$. Chemiluminescent signals were developed with an ECL Kit (ECL, Engreen) and exposed to Xray films in a dark room. Then the membranes were stripped by a stripping buffer (SinoGene Scientific) and reprobed with $\beta$-actin (M20010, Abmart). The level of actin was measured as an internal control.

2.10. RT-PCR Analysis. Total RNA was separated from samples with a SG TriEx HiPure RNA Extraction Kit (SinoGene Scientific, China). RNA concentration was measured at $260 \mathrm{~nm}$ and its purity was assessed with Biophotometer (Eppendorf, Germany) at a ratio of $260: 280 \mathrm{~nm}$. RNA samples were processed with DNaseI (EN0523, Fermentas) to clear away the contaminated genomic DNA and analyzed on $1.5 \%$ agarose gels. Reverse transcription was performed through a Thermo First cDNA Synthesis Kit (SinoGene Scientific China) with random hexamer primers. The average amount of RNA used in the reverse transcription reaction was $1 \mu \mathrm{g}$ and its purity was around $2.0(260: 280 \mathrm{~nm}$ ratio).

qPCR per tube contained $10 \mu \mathrm{L}$ of $2 \mathrm{x}$ SG Green qPCR Mix (with ROX), (SinoGene Scientific, China), $250 \mathrm{nM}$ of each primer (list of primers as Table 1), PCR grade water, and $1 \mu \mathrm{L}$

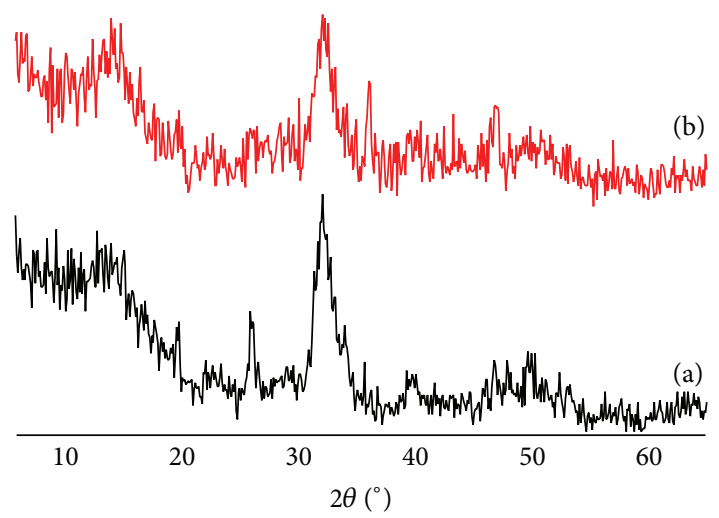

FIGURE 2: XRD patterns of nanoparticles ((a) n-HA; (b) n-HAcoated magnetic nanoparticles).

of cDNA template (diluted in a $1: 2$ or $1: 10$ ratio). All samples were assayed in duplicate with each run. The PCR cycling program consisted of $10 \mathrm{~min}$ at $95^{\circ} \mathrm{C}$, followed by 40 cycles of $15 \mathrm{~s}$ at $95^{\circ} \mathrm{C}$ and $60 \mathrm{~s}$ at $58^{\circ} \mathrm{C}$. An additional step was used $\left(95^{\circ} \mathrm{C}\right.$ for $15 \mathrm{~s}, 58^{\circ} \mathrm{C}$ or $55^{\circ} \mathrm{C}$ for $30 \mathrm{~s}$, and $95^{\circ} \mathrm{C}$ for $15 \mathrm{~s}$ ) for dissociation curve analysis.

2.11. Statistical Analysis. The data are defined as the mean \pm S.E.M. In terms of statistical comparison, this research adopted the $t$-test or one-way ANOVA as well as Tukey's test. ${ }^{*} P<0.05,{ }^{* *} P<0.01$, and ${ }^{* * *} P<0.001$ were deemed to be of statistical significance.

\section{Results}

3.1. XRD Measurement. X-ray diffraction of the synthesized materials would generate characteristic peaks (see Figure 2). These were broad diffraction peaks, which indicated a weak crystal construct, a representative of nonstoichiometric HA (referred from JCPDS 09-0432). With the Jade 9.0 software, the average particle size of synthesized HA could be measured as $28.47 \pm 0.4 \mathrm{~nm}$ in the $\mathrm{n}$-HA-coated magnetic nanoparticles system, and the characteristic peaks of $\mathrm{Fe}_{3} \mathrm{O}_{4}$ also appeared in Figure 2(b). The diffraction peaks at $36.51^{\circ}, 47.09^{\circ}, 57.08^{\circ}$, and $62.96^{\circ}$ corresponding to the planes of (311), (400), (333), and (440) clearly proved the pattern of the spinal structures on ferrite. This result conforms to former publications of similar phenomena. Nevertheless, the samples presented such variations in crystalline structure. In this regard, HA, with a space group of $\mathrm{P} 63 / \mathrm{m}, a=b=0.935 \sim 0.947 \mathrm{~nm}$ and $c=0.677 \sim 0.692 \mathrm{~nm}$, is in the hexagonal system. According to Rietveld analysis, there was a rise of the axis from 0.9407 to 0.9429 and a rise of $c$ axis from 0.6878 to 0.6881 due to the Ca replacement with ion species at a smaller radius. Contrasted with the HA group, $a, b$, and $c$ axes all grew within the n-HA-coated magnetic nanoparticles. With coating n$\mathrm{HA}$, the nanocomposite's cell structure rose to $0.5282 \mathrm{~nm}^{3}$. These variations correspondingly reflect the distortion of HA. The distortion might be explained as follows: the magnetic iron oxide particles substituted $-\mathrm{OH}$, which is parallel to the $c$ axis, and subsequently they enter the HA crystal lattice, which 


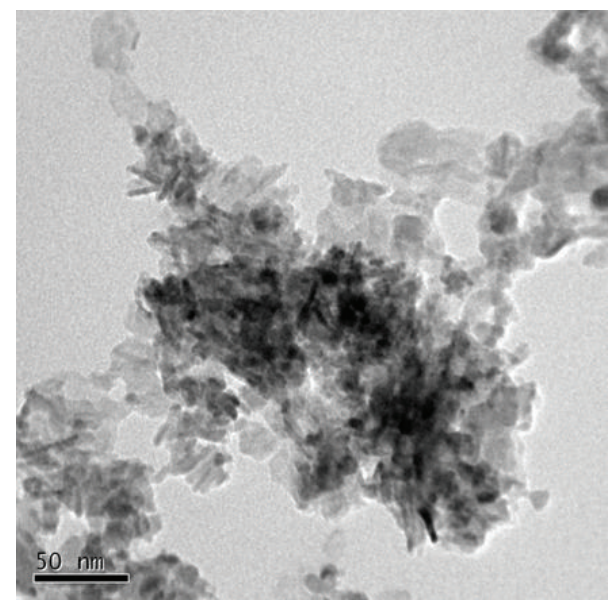

FIGURE 3: TEM of n-HA-coated magnetic nanoparticles.

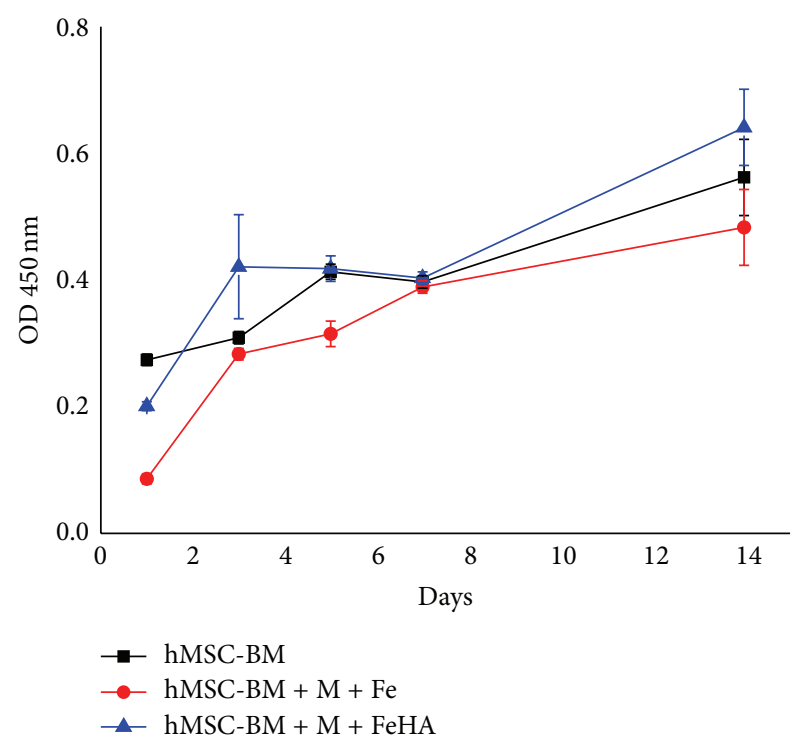

FIGURE 4: In vitro cell proliferation of nanoparticles materials.

leads to such variations on the crystal surface of HA (210) and (212). Coordinating with $\mathrm{PO}_{4}{ }^{3-}$ of $\mathrm{HA}$, the $\mathrm{Fe}$ ion in $\mathrm{Fe}_{3} \mathrm{O}_{4}$ serves as a bridge to $\mathrm{PO}_{4}{ }^{3-}$ groups, becoming another reason for the variations in the HA unit cells.

3.2. TEM Observation. By investigating the morphology of $\mathrm{n}$ HA-coated magnetic nanoparticles through TEM analysis, it was observed that a low concentration of dark spots $(2-4 \mathrm{~nm}$ in size) corresponded to the inclusions of iron-rich phases (Figure 3). The $\mathrm{Fe}_{3} \mathrm{O}_{4}$ - $\mathrm{HA}$ composite was found to be quite heterogeneous in size, with 1-5 $\mathrm{nm}$ wide but reaching 15$40 \mathrm{~nm}$ long (Figure 3).

3.3. CCK8 Analysis. A CCK-8 assay was used to evaluate the cytotoxicity of the magnetic nanoparticles, and the OD values could indicate the cellular viability and multiplication on diverse materials. As seen in Figure 4, the OD values for the
n-HA-coated magnetic nanoparticles increased with culture duration, which indicated that this particular scaffold had no detrimental effect on the viability and proliferation of hMSC$\mathrm{BM}$ cells. In addition, this trend suggested that the n-HAcoated magnetic nanoparticles had a better biocompatibility than the Fe magnetic nanoparticles.

3.4. SEM Observation. The morphologies of n-HA-coated magnetic nanoparticles under magnetic stimulation were investigated by SEM. The results proved that n-HA-coated magnetic nanoparticles were noncytotoxic and could support hMSC-BM attachment, spreading, and proliferation. The inductivity of these nanobiomaterials reveals an important role of cell growth (Figure 5). Due to their high surface-tovolume ratio, the nanobiomaterials could arouse a higher level of biological plasticity. Besides, the morphology and nanoscale structure in the surface of n-HA-coated magnetic nanoparticle also accelerated the rate of hMSC-BM proliferation.

3.5. Immunofluorescence Assay. Consisting of a great variety of particular proteins, the cell skeleton itself is an extremely dynamical system, which plays multiple roles in human diseases. To study the growth behaviors of hMSC-BM cells in three unlike materials, this research visualized the cells by the double staining technique in both cell skeleton and nucleus. In addition, fluorescence microscopy was employed to watch reorganization of cell skeleton after 7-day incubation (Figure 6). Cells processed with HA presented the stretched and linear arrays of actin microfilaments (Figure 6(c)). Moreover, cells also displayed the characteristics of osteoblast cells like the clear and big nucleus and spindle or polygonal appearance. Therefore, cell skeleton was clearly visible, and actin fibers were in bundles, each arranged in parallel and consistent with the long axis of the cell. However, there were limited cells on the $\mathrm{Fe}_{3} \mathrm{O}_{4}$ group, cell skeleton was fuzzy, and some actin fibrin concentrated together (Figure 6(b)). Compared with the control (Figure 6(a)), the $\mathrm{Fe}_{3} \mathrm{O}_{4}-\mathrm{HA}$ composite (Figure 6(c)) presented excellent cytoskeletal reorganization. HA enhanced biocompatibility of $\mathrm{Fe}_{3} \mathrm{O}_{4}$ by coupling strategy which processed a composite build-up. Based on this analysis, it could be concluded that $\mathrm{Fe}_{3} \mathrm{O}_{4}$ HA composites were noncytotoxic to hMSC-BM cells and equipped with great biocompatibility.

3.6. ALP Analysis. The gradual and progressive increase of ALP activity during the process of osteogenic differentiation could be found in both Fe and nHA groups, which suggested the successful osteogenic differentiation (Figure 7). Presented in the osteoblast membrane and participated in the synthesis and mineralisation of the bone matrix, the enzyme ALP is one of the most widely used markers of in vitro osteogenic differentiation $[35,36]$. Its expression may increase up to 27 times during the process of osteogenic differentiation [37-40] under the magnetic situation.

3.7. Western Blot and PCR Analysis. In order to further confirm the differentiation of hMSC-BM cells, the expression of OCN and OPN was analyzed on the 3rd day and the 


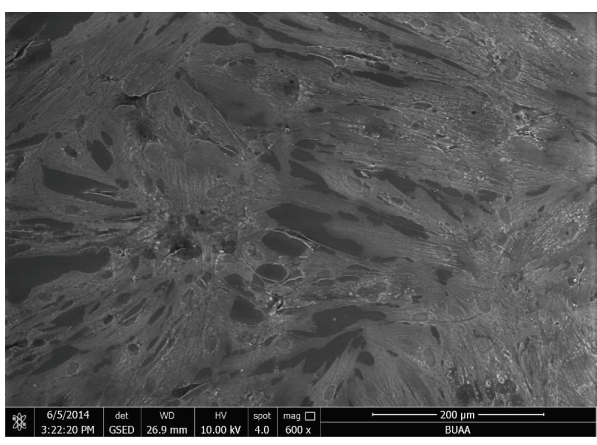

(a)

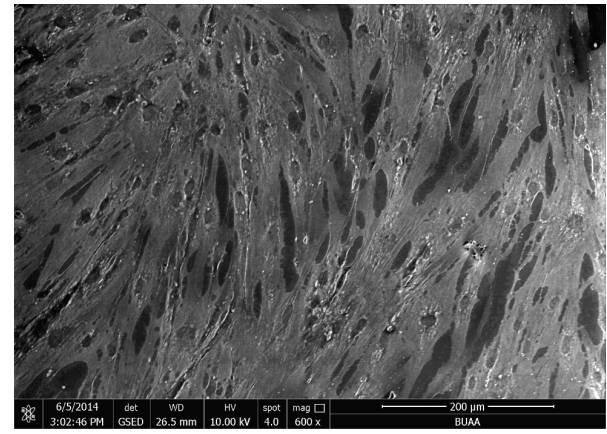

(b)

FIGURE 5: SEM of cell growth ((a) control without materials; (b) cocultured with $\mathrm{Fe}_{3} \mathrm{O}_{4}$-HA).

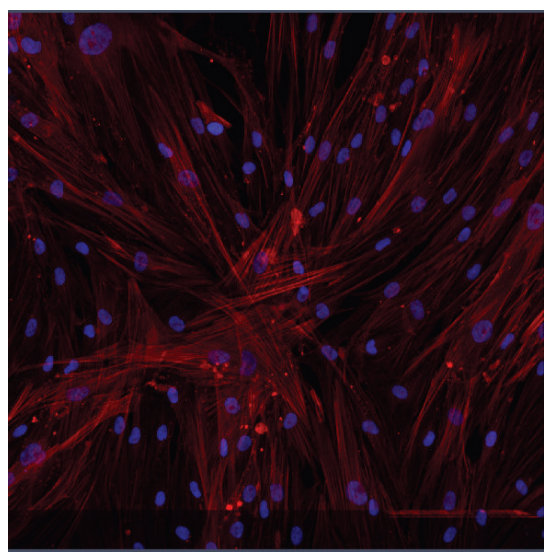

(a)

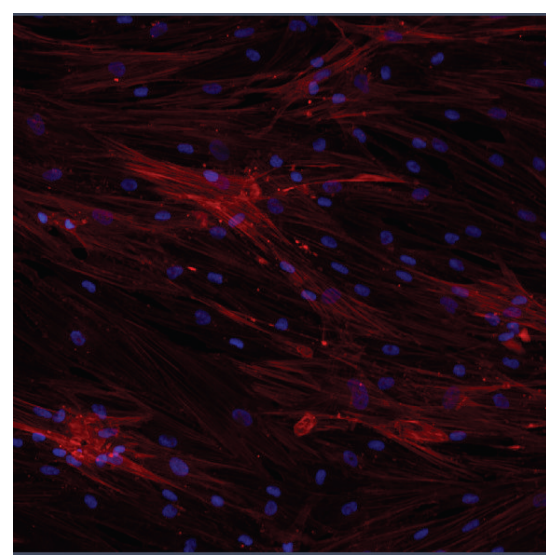

(b)

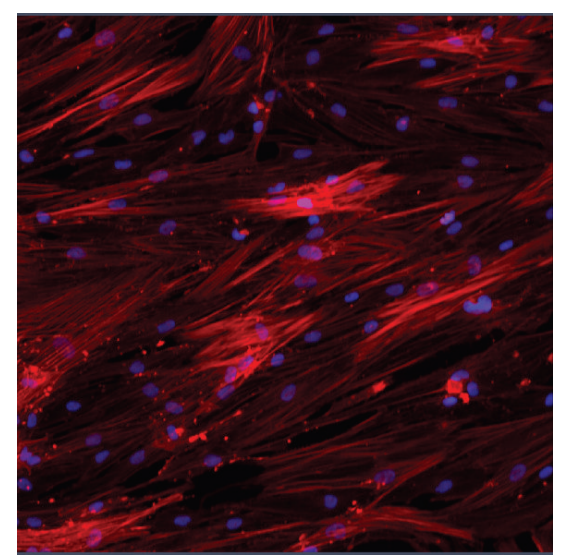

(c)

FIGURE 6: Fluorescence images for the organization of cell skeleton in hMSC-BM cells cocultured with different materials ((a) control without materials; (b) $\mathrm{Fe}_{3} \mathrm{O}_{4}$; (c) $\mathrm{Fe}_{3} \mathrm{O}_{4}$-HA) after seven days. Cells were stained as F-actin (red) and nucleus (blue). Scale bar $50 \mu \mathrm{m}$.

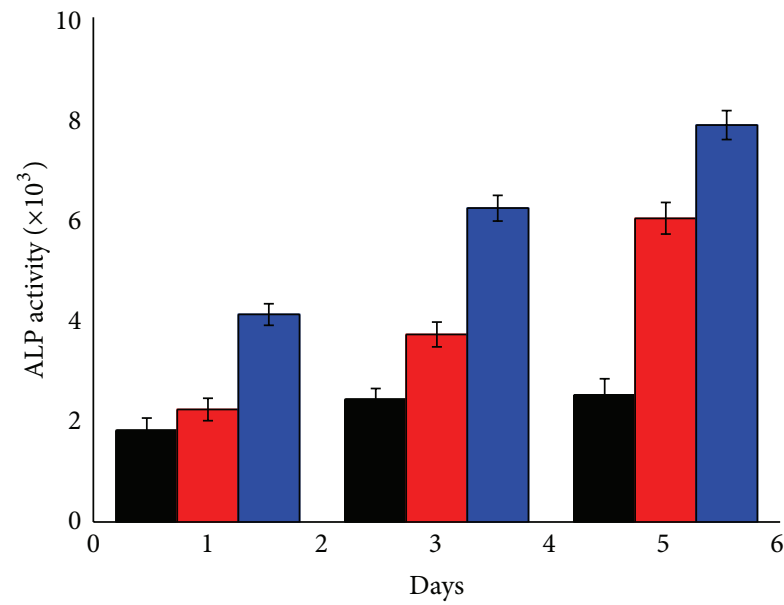

hMSC-BM

hMSC-BM $+\mathrm{M}+\mathrm{Fe}$

hMSC-BM + M + FeHA

FIGURE 7: In vitro ALP activity of cell cocultured with nanoparticles.

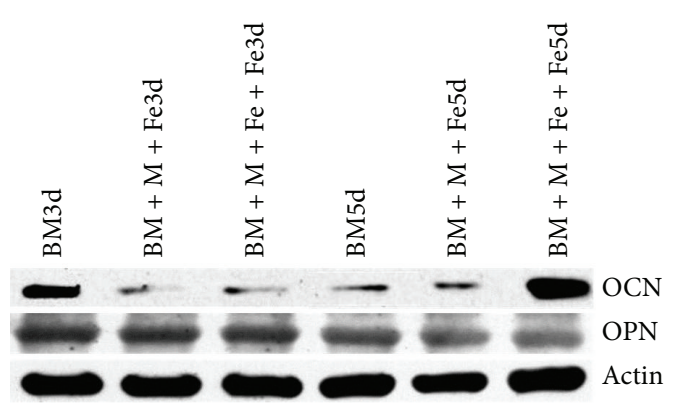

FIgURE 8: The Western blot results of osteoblast-related genes OCN and OPN expressions of hMSC-BM. On the 5th day, the expression levels of OCN and OPN increased contrast with the CON group.

5th day after culturing on the induced medium by Western blot (Figure 8). On the 3rd day, the expression levels of OCN and OPN decreased in contrast with the CON group, while on the 5th day, the expressions of OCN and OPN 

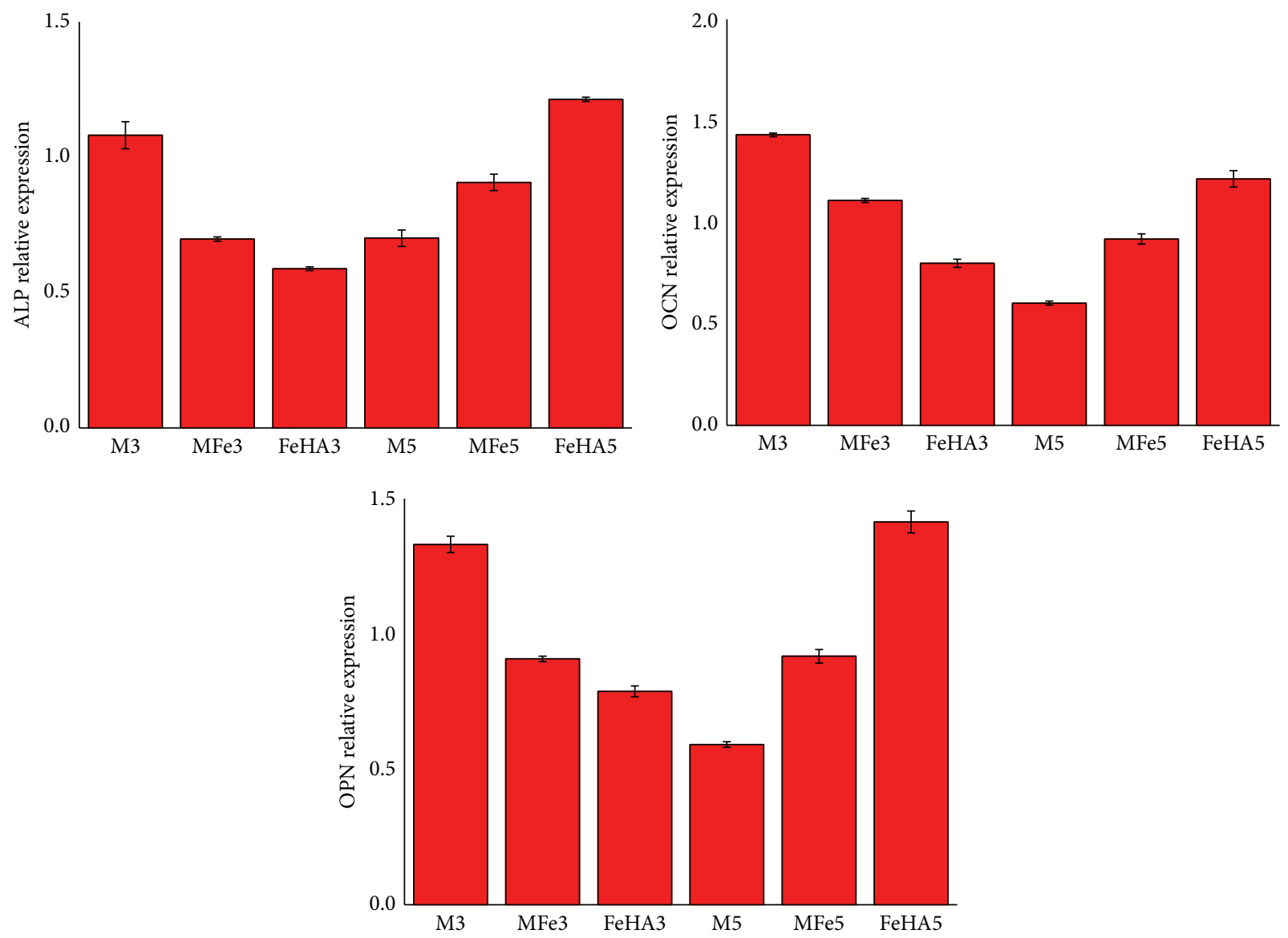

FIGURE 9: Impacts of different materials on osteoblast-related genes ALP, OCN, and OPN expressions of hMSC-BM. The results were expressed in the form of mean \pm SD values. In contrast with the CON group, on the 5th day of treatment, the expression levels of genes ALP, OCN, and OPN increased $(P<0.05)$.

increased in $\mathrm{Fe}$ and nHA group compared with the $\mathrm{CON}$ group. Inductions of osteoblast specific genes ALP, OCN, and OPN were examined by RT-PCR. Compared with the control group, the expression levels of genes OCN, OPN, and ALP increased in the treatment of the 5th day $(P<0.05)$ under the magnetic situation. The results of qPCR were consistent with the WB analysis, which showed that the expressions of ALP, $\mathrm{OCN}$, and OPN increased in contrast with the CON group on the 5th day. The fold-change of gene expression data is shown in Figure 9.

\section{Discussion}

Recently, the nanoscale magnetic material has become a hotspot in the biomaterials field. Biocompatibility [24] is particularly significant in the magnetic nanoparticles. Moreover, it shall not arouse any unfavorable systemic or local influences on the beneficiary or recipient of the treatment. Instead, it is desired that the most proper beneficial cellular or tissue reaction under that particular condition can be generated and the related beneficial clinical performance of that treatment can be optimized. In this regard, the Fe-based particles occupy a great share in the magnetic nanoparticles. However, Fe revealed some toxicity in its clinical application. Some study thus attempted to improve the Fe-based magnetic particles. For example, Latham and Williams explored to synthesize $\mathrm{Fe}_{3} \mathrm{O}_{4}$ improved by polymer so as to reduce the cell toxicity and enhance biocompatibility [22]. In this research, the second-phase theory was applied to form the n-HA-coated magnetic nanoparticles, because n-HA could increase the osteoinductivity of $\mathrm{Fe}_{3} \mathrm{O}_{4}$. As the results of the SEM survey and immunofluorescence assay indicated, the $\mathrm{Fe}_{3} \mathrm{O}_{4}$-HA composites could vigorously support the hMSC-BM attachment, proliferation, and spreading. In other words, $\mathrm{Fe}_{3} \mathrm{O}_{4}$ - $\mathrm{HA}$ magnetic particles exerted no cytotoxicity to hMSC-BM cells and owned perfect biocompatibility. In addition, HA, the second phase, improved the inductivity of those nanobiomaterials. It is known to all that the inductivity plays a vital role in cellular growth. In this regard, efficient approaches of artificial control in scale and shape for $\mathrm{Fe}_{3} \mathrm{O}_{4}$ and surface modification of $\mathrm{Fe}_{3} \mathrm{O}_{4}$ are usually adopted to lower the toxicity in $\mathrm{Fe}_{3} \mathrm{O}_{4}$. However, some scientists proved that, through artificial coating and modification, $\mathrm{Fe}_{3} \mathrm{O}_{4}$ would lose its original characteristics, which are thus unparallel to the original ones in a basic sense. In specific, the second-phase modifying approaches include 
the chemical modification and surface coat. By modifying the $\mathrm{Fe}_{3} \mathrm{O}_{4}$, the inherent toxicity in $\mathrm{Fe}_{3} \mathrm{O}_{4}$ can be lowered. Therefore, it can significantly enhance the biocompatibility of $\mathrm{Fe}_{3} \mathrm{O}_{4}$. In order to safely apply $\mathrm{Fe}_{3} \mathrm{O}_{4}$ in biomedicine, the new magnetic nanoparticles shall be equipped with high biocompatibility but low toxicity. From these data of results, the synthesized $\mathrm{Fe}_{3} \mathrm{O}_{4}$-HA magnetic particles showed prefect biocompatibility and no cytotoxicity.

Besides, magnet can influence the flow of ions within the cells, especially the flow of $\mathrm{Ca}^{2+}$. It can directly or indirectly cause the reconstruction of microfilaments, surficial glycosyl, and micropipes and finally influence the cellular morphology and cellular membrane growth. Nonetheless, the majority of researches aimed to characterize the biocompatibility of magnetic nanoparticles without considering the magnetic condition. Recently, an increasing number of scientists have discovered that magnetic condition can facilitate the bone regeneration. Therefore, the biocompatibility of the $\mathrm{Fe}_{3} \mathrm{O}_{4}$ HA magnetic particle will be studied in the magnetic situation. With the biocompatible nanosized magnetic particles as a remote force mechanism without invading the sterile bioreactor environment, this paper specifically demonstrated the theoretical base, design, and preliminary results of a mechanically conditioning system for cellular culture. The magnetic force bioreactor was created for the magnetic condition. From Figure 1, it can be found that the cell disc can be located in the middle of the magnetic force bioreactor. The distribution of magnetic induction line can form between the different polarity magnets facing each other. The cells cultured with $\mathrm{Fe}$ and n-HA were seeded in plates with culture medium and exposed to a magnetic force bioreactor every one hour at every other day of cyclic loading intervals for a 14-day period. The magnetic flux density of the central field is up to $0.2 \mathrm{~T}$. The mechanical condition of cellular structure in bioreactors is a vital element determining the characteristics of the generated tissue. It is the magnetic force bioreactor that produces the magnetic stress. Therefore, the mechanical condition under a bioreactor situation can be controlled. This new bioreactor is designed to solve problems with the ex vivo development of mechanically stable, functional, and connective tissues. The present bioreactors are relatively limited, because the biochemical reactions need to be initiated within cells which grow upon the biodegradable scaffold in the bioreactor through applying the mechanical force into the cellular membranes. The bioreactor with magnetic force is designed to utilize the force directly into the cellular membranes through coupling the biocompatible nanosized magnetic particles into the receptor sites and membrane surfaces. Aiming at deforming the cellular membranes and activating the mechanosensitive transmembrane $\mathrm{Ca}^{2+}$ channels, the forces on the sequence of some piconewtons are demanded. The deformation in the membranes as well as the activation in those ion channels will make the biochemical reaction cascades become necessary for the growth of functional tissues. Hence, mechanically weak scaffold materials can be utilized if these small forces are directly applied into the membranes. This is because the applied forces are generated remotely through connecting these particles into external fields. During this process, the system can be closed so as to prevent infection. Besides, forces applied to the nanosized magnetic particles may be spatially different in 3 dimensions by changing the distance of different areas of the nanosized particles to the field source or through varying the properties of magnetic particles in various regions of the nanosized particles. The bioreactor can be further applied in human tissue in the future.

According to the analysis in this paper, it mainly finds that the nanoscale n-HA-coated magnetic $\left(\mathrm{Fe}_{3} \mathrm{O}_{4}-\mathrm{HA}\right)$ particles prefer osteoblast from hMSC-BM, because of the $\mathrm{Fe}_{3} \mathrm{O}_{4}$. n$\mathrm{HA}$ increased the osteoinductivity of $\mathrm{Fe}_{3} \mathrm{O}_{4}$. Moreover, it is indicated that $\mathrm{n}$-HA modifies the microenvironment of cellular culture which exerts great influences on the differentiation of hMSC-BM. Specifically, n-HA gathers protein, shapes neomatrix, and greatly improves osteogenesis. The expression of ALP can rise up to 27 times in the magnetic condition compared with control. Based on the Western blot and PCR analysis, it can be easily observed that the expression level of genes OCN, ALP, and OPN was enhanced on the treatment of the 5th day $(P<0.05)$ in the magnetic condition. This indicates that the magnetic condition can greatly affect the cellular growth and cellular differentiation. For this project, an understanding of the magnetic forces may affect the interaction of the particles with the cell. In addition, the nanosize of n-HA-coated magnetic particles also plays a vital part in the fate of the stem cells. Particles of diameter less than $50 \mathrm{~nm}$ will act as the superparamagnets, which means they will become the paramagnetic materials with high susceptibility, while particles with diameter above $50 \mathrm{~nm}$ will serve as permanent magnetic dipoles. As the diameter of nanoscale n-HA-coated magnetic $\left(\mathrm{Fe}_{3} \mathrm{O}_{4}\right.$-HA) particles was around $15-40 \mathrm{~nm}$, they belong to the superparamagnets. Attributing to their physicochemical characteristics, both nanomaterials and microparticles [41-43] have shown some cell toxicity and biostability. On the other hand, the cellular death was significantly correlated with its particle load. The particles were avoiding the phagocytic passage and a few even entered the nuclei through nuclear pores. It means that the number of nanoparticles must be normalized and controlled with target stem cell. Even if the engineered biomaterials are seeded with the stem cell, they will be regarded as the differentiation of cells in some situations. The appropriately designed size of nanomaterials is a potential and promising way for the clinical repair of tissues. Therefore, the nHA-coated magnetic $\left(\mathrm{Fe}_{3} \mathrm{O}_{4}\right.$-HA) particles were concluded with better biocompatibility, which provided some useful information for its clinical applications.

\section{Conclusions}

To summarize, the n-HA-coated magnetic nanoparticles (n$\mathrm{HA} / \mathrm{Fe}_{3} \mathrm{O}_{4}$ ) were prepared through precipitation approach. n-HA-coated magnetic nanoparticles increased cell viability and promoted hMSC-BM growth under magnetic situation. $\mathrm{n}-\mathrm{HA} / \mathrm{Fe}_{3} \mathrm{O}_{4}$ increase up the process of osteogenic differentiation under the magnetic situation. Therefore, it will be a promising approach for bone engineering in future. 


\section{Conflict of Interests}

The authors declare no possible conflict of interests.

\section{Authors' Contribution}

Qing Li and Gang Zhou contributed equally to this paper.

\section{Acknowledgments}

This study was supported by funds from National Natural Science Foundation of China (NSFC) Research Grant (nos. 81171000, 31100666, 11120101001, 61227902, 11172031, 10925208, and 51302005), the National High Technology Research and Development Program of China (2012AA022501), Science Foundation of Beijing Research Grant (no. Z121100005212009), the Key International S\&T Cooperation Project (no. 2011DFA32190), National Basic Research Program of China (973 program, 2011CB710901 and 2012CB933900), National Key Technology R\&D Program (nos. 2012BAI18B06, 2012BAI18B05, and 2012BAI07B01), the 111 Project of China (no. B13003), International Joint Research Center of Aerospace Biotechnology and Medical Engineering, Ministry of Science and Technology of China, Doctoral Scientific Fund Project of the Ministry of Education of China (no. 20130001120112), and the Fundamental Research Funds for the Central Universities of China. Additionally, the authors also acknowledge the support of the Peking University-Tsinghua University Joint Center for Life Sciences.

\section{References}

[1] I. V. Vasylenko, S. V. Kolotilov, I. E. Kotenko et al., "Magnetic properties of nanosized $\gamma-\mathrm{Fe}_{2} \mathrm{O}_{3}$ and $\alpha-\left(\mathrm{Fe}_{2 / 3} \mathrm{Cr}_{1 / 3}\right)_{2} \mathrm{O}_{3}$, prepared by thermal decomposition of heterometallic singlemolecular precursor," Journal of Magnetism and Magnetic Materials, vol. 324, no. 4, pp. 595-601, 2012.

[2] X. Li, Y. Yang, Y. Fan, Q. Feng, F.-Z. Cui, and F. Watari, "Biocomposites reinforced by fibers or tubes as scaffolds for tissue engineering or regenerative medicine," Journal of Biomedical Materials Research-Part A, vol. 102, no. 5, pp. 1580-1594, 2014.

[3] X. Li, C. A. van Blitterswijk, Q. Feng, F. Cui, and F. Watari, “The effect of calcium phosphate microstructure on bone-related cells in vitro," Biomaterials, vol. 29, no. 23, pp. 3306-3316, 2008.

[4] Q. Wu, X. L. Zhang, B. Wu, and W. Huang, "Effects of microwave sintering on the properties of porous hydroxyapatite scaffolds," Ceramics International, vol. 39, no. 3, pp. 2389-2395, 2013.

[5] G. A. O. Jinhao, G. U. Hongwei, and X. U. Bing, "Multifunctional magnetic nanoparticles: design, synthesis, and biomedical applications," Accounts of Chemical Research, vol. 42, no. 8, pp. 1097-1107, 2009.

[6] G. Unsoy, R. Khodadust, S. Yalcin, P. Mutlu, and U. Gunduz, "Synthesis of Doxorubicin loaded magnetic chitosan nanoparticles for $\mathrm{pH}$ responsive targeted drug delivery," European Journal of Pharmaceutical Sciences, vol. 62, pp. 243-250, 2014.

[7] S. Venkateswarlu, B. N. Kumar, C. H. Prasad, P. Venkateswarlu, and N. V. V. Jyothi, "Bio-inspired green synthesis of $\mathrm{Fe}_{3} \mathrm{O}_{4}$ spherical magnetic nanoparticles using Syzygium cumini seed extract," Physica B: Condensed Matter, vol. 449, pp. 67-71, 2014.
[8] C. Wilhelm and F. Gazeau, "Universal cell labelling with anionic magnetic nanoparticles," Biomaterials, vol. 29, no. 22, pp. 31613174, 2008.

[9] A. Ito, E. Hibino, H. Honda et al., "A new methodology of mesenchymal stem cell expansion using magnetic nanoparticles," Biochemical Engineering Journal, vol. 20, no. 2-3, pp. 119-125, 2004.

[10] K. Shimizu, A. Ito, T. Yoshida, Y. Yamada, M. Ueda, and H. Honda, "Bone tissue engineering with human mesenchymal stem cell sheets constructed using magnetite nanoparticles and magnetic force," Journal of Biomedical Materials Research Part B: Applied Biomaterials, vol. 82, no. 2, pp. 471-480, 2007.

[11] G. Zhou, A. Ruhan, H. Ge et al., "Research on a novel poly (vinyl alcohol)/lysine/vanillin wound dressing: Biocompatibility, bioactivity and antimicrobial activity," Burns, vol. 40, no. 8 , pp. 1668-1678, 2014.

[12] V. N. Binhi, Y. D. Alipov, and I. Y. Belyaev, "Effect of static magnetic field on E. coli cells and individual rotations of ionprotein complexes," Bioelectromagnetics, vol. 22, no. 2, pp. 79$86,2001$.

[13] A. Chionna, B. Tenuzzo, E. Panzarini, M. B. Dwikat, L. Abbro, and L. Dini, "Time dependent modifications of Hep G2 cells during exposure to static magnetic fields," Bioelectromagnetics, vol. 26, no. 4, pp. 275-286, 2005.

[14] A. D. Rosen, "Membrane response to static magnetic fields: effect of exposure duration," Biochimica et Biophysica Acta, vol. 1148, no. 2, pp. 317-320, 1993.

[15] S. H. Hamada, R. Witkus, and R. Griffith Jr., "Cell surface changes during electromagnetic field exposure," Experimental Cell Biology, vol. 57, no. 1, pp. 1-10, 1989.

[16] A. Chionna, M. Dwikat, E. Panzarini et al., "Cell shape and plasma membrane alterations after static magnetic fields exposure," European Journal of Histochemistry, vol. 47, no. 4, pp. 299308, 2003.

[17] A. Nel, T. Xia, L. Mädler, and N. Li, “Toxic potential of materials at the nanolevel," Science, vol. 311, no. 5761, pp. 622-627, 2006.

[18] T. Xia, N. Li, and A. E. Nel, "Potential health impact of nanoparticles," Annual Review of Public Health, vol. 30, pp. 137150, 2009.

[19] V. I. Shubayev, T. R. Pisanic II, and S. Jin, "Magnetic nanoparticles for theragnostics," Advanced Drug Delivery Reviews, vol. 61, no. 6, pp. 467-477, 2009.

[20] V. Lorusso, L. Pascolo, C. Fernetti, P. L. Anelli, F. Uggeri, and C. Tiribelli, "Magnetic resonance contrast agents: from the bench to the patient," Current Pharmaceutical Design, vol. 11, no. 31, pp. 4079-4098, 2005.

[21] H. Rui, R. J. Xing, Z. C. Xu, Y. L. Hou, S. Goo, and S. H. Sun, "Synthesis, functionalization, and biomedical applications of multifunctional magnetic nanoparticles," Advanced Materials, vol. 22, no. 25, pp. 2729-2742, 2010.

[22] A. H. Latham and M. E. Williams, "Controlling transport and chemical functionality of magnetic nanoparticles," Accounts of Chemical Research, vol. 41, no. 3, pp. 411-420, 2008.

[23] A. Tsetsekou, D. Brasinika, V. Vaou, and E. Chatzitheodoridis, "On the synthesis of tailored biomimetic hydroxyapatite nanoplates through a bioinspired approach in the presence of collagen or chitosan and l-arginine," Materials Science and Engineering C: Materials for Biological Applications, vol. 43, pp. 555$565,2014$.

[24] X. Li, Y. Huang, L. Zheng et al., "Effect of substrate stiffness on the functions of rat bone marrow and adipose tissue 
derived mesenchymal stem cells in vitro," Journal of Biomedical Materials Research Part A, vol. 102, no. 4, pp. 1092-1101, 2014.

[25] A. M. Sofronia, R. Baies, E. M. Anghel, C. A. Marinescu, and S. Tanasescu, "Thermal and structural characterization of synthetic and natural nanocrystalline hydroxyapatite," Materials Science and Engineering C: Materials for Biological Applications, vol. 43, pp. 153-163, 2014.

[26] X. Li, Q. Feng, X. Liu, W. Dong, and F. Cui, "Collagen-based implants reinforced by chitin fibres in a goat shank bone defect model," Biomaterials, vol. 27, no. 9, pp. 1917-1923, 2006.

[27] F. Mohandes, M. Salavati-Niasari, Z. Fereshteh, and M. Fathi, "Novel preparation of hydroxyapatite nanoparticles and nanorods with the aid of complexing agents," Ceramics International, vol. 40, no. 8, pp. 12227-12233, 2014.

[28] R. Drevet, H. Benhayoune, and J. Michel, "Structural characterization of electrodeposited strontium substituted calcium phosphate coatings," Journal of Biomaterials and Tissue Engineering, vol. 1, no. 1, pp. 68-75, 2011.

[29] M. Bricha, Y. Belmamouni, E. M. Essassi, J. M. F. Ferreira, and K. E. Mabrouk, "Hydrothermal synthesis and appraisal of mgdoped hydroxyapatite nanopowders," Journal of Biomaterials and Tissue Engineering, vol. 3, no. 5, pp. 570-580, 2013.

[30] S. Johnsen and K. J. Lohmann, "The physics and neurobiology of magnetoreception," Nature Reviews Neuroscience, vol. 6, no. 9, pp. 703-712, 2005.

[31] R. Wiltschko and W. Wiltschko, "Magnetoreception," BioEssays, vol. 28, no. 2, pp. 157-168, 2006.

[32] M. Feychting, A. Ahlbom, and L. Kheifets, "EMF and health," Annual Review of Public Health, vol. 26, pp. 165-189, 2005.

[33] L. Dini and L. Abbro, "Bioeffects of moderate-intensity static magnetic fields on cell cultures," Micron, vol. 36, no. 3, pp. 195217, 2005.

[34] G. Zhou, W. Song, Y. Hou, Q. Li, X. Deng, and Y. Fan, "Ultrasound-assisted fabrication of a biocompatible magnetic hydroxyapatite," Journal of Biomedical Materials Research Part A, vol. 102, no. 10, pp. 3704-3712, 2014.

[35] X. Li, H. Gao, M. Uo et al., "Effect of carbon nanotubes on cellular functions in vitro," Journal of Biomedical Materials Research Part A, vol. 91, no. 1, pp. 132-139, 2009.

[36] X. Li, H. Liu, X. Niu et al., "Osteogenic differentiation of human adipose-derived stem cells induced by osteoinductive calcium phosphate ceramics," Journal of Biomedical Materials Research, Part B Applied Biomaterials, vol. 97, no. 1, pp. 10-19, 2011.

[37] A. A. Eid, K. A. Hussein, L. N. Niu et al., "Effects of tricalcium silicate cements on osteogenic differentiation of human bone marrow-derived mesenchymal stem cells in vitro," Acta Biomaterialia, vol. 10, no. 7, pp. 3327-3334, 2014.

[38] S. Chen, D. A. Ryan, M. A. Dwyer, and J. R. Cashman, "Synergistic effect of Wnt modulatory small molecules and an osteoinductive ceramic on $\mathrm{C} 2 \mathrm{C} 12$ cell osteogenic differentiation," Bone, vol. 67, pp. 109-121, 2014.

[39] M. Kassem, B. M. Abdallah, and H. Saeed, "Osteoblastic cells: differentiation and transdifferentiation," Archives of Biochemistry and Biophysics, vol. 473, no. 2, pp. 183-187, 2008.

[40] C. Wu, Y. Zhou, C. Lin, J. Chang, and Y. Xiao, "Strontiumcontaining mesoporous bioactive glass scaffolds with improved osteogenic/cementogenic differentiation of periodontal ligament cells for periodontal tissue engineering," Acta Biomaterialia, vol. 8, no. 10, pp. 3805-3815, 2012.

[41] A. M. Mebert, D. E. Camporotondi, M. L. Foglia et al., "Controlling the interaction between cells and silica nanoparticles,"
Journal of Biomaterials and Tissue Engineering, vol. 3, no. 1, pp. 108-121, 2013.

[42] X. Li, Y. Fan, and F. Watari, "Current investigations into carbon nanotubes for biomedical application," Biomedical Materials, vol. 5, no. 2, Article ID 022001, 2010.

[43] H. T. Jin, S. Y. Liu, F. F. Guo, and B. B. Zhang, "Polymercoated superparamagnetic iron oxide nanoparticles: synthesis, characterization and toxicity evaluation for MRI in mice," Journal of Biomaterials and Tissue Engineering, vol. 4, no. 6, pp. 443-449, 2014. 

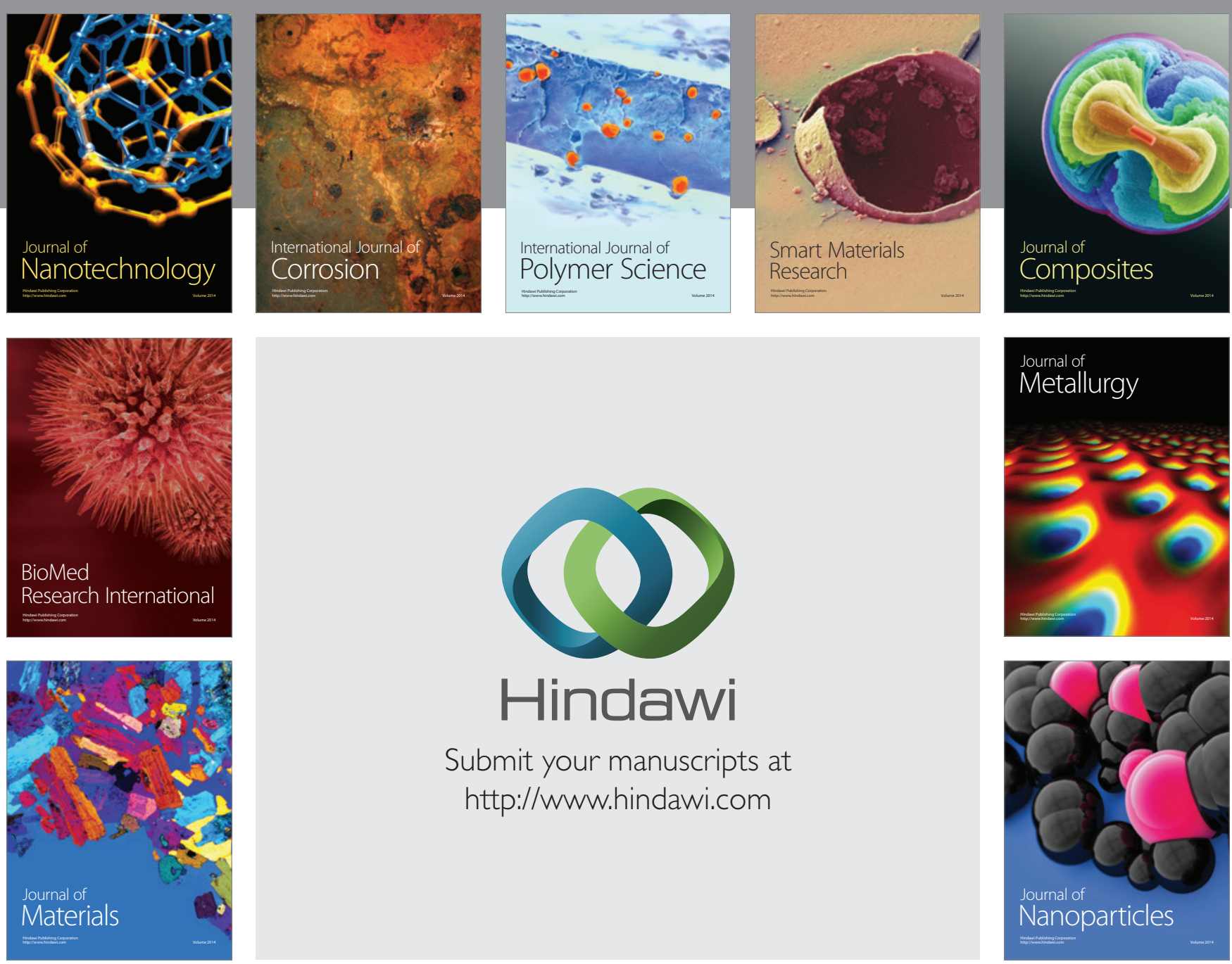

Submit your manuscripts at http://www.hindawi.com
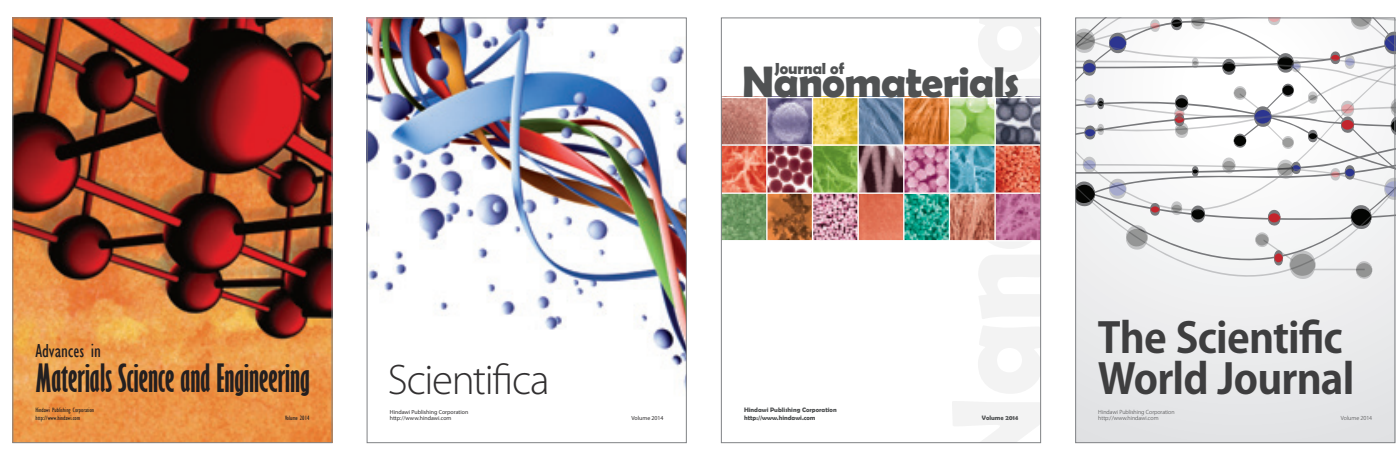

\section{The Scientific World Journal}
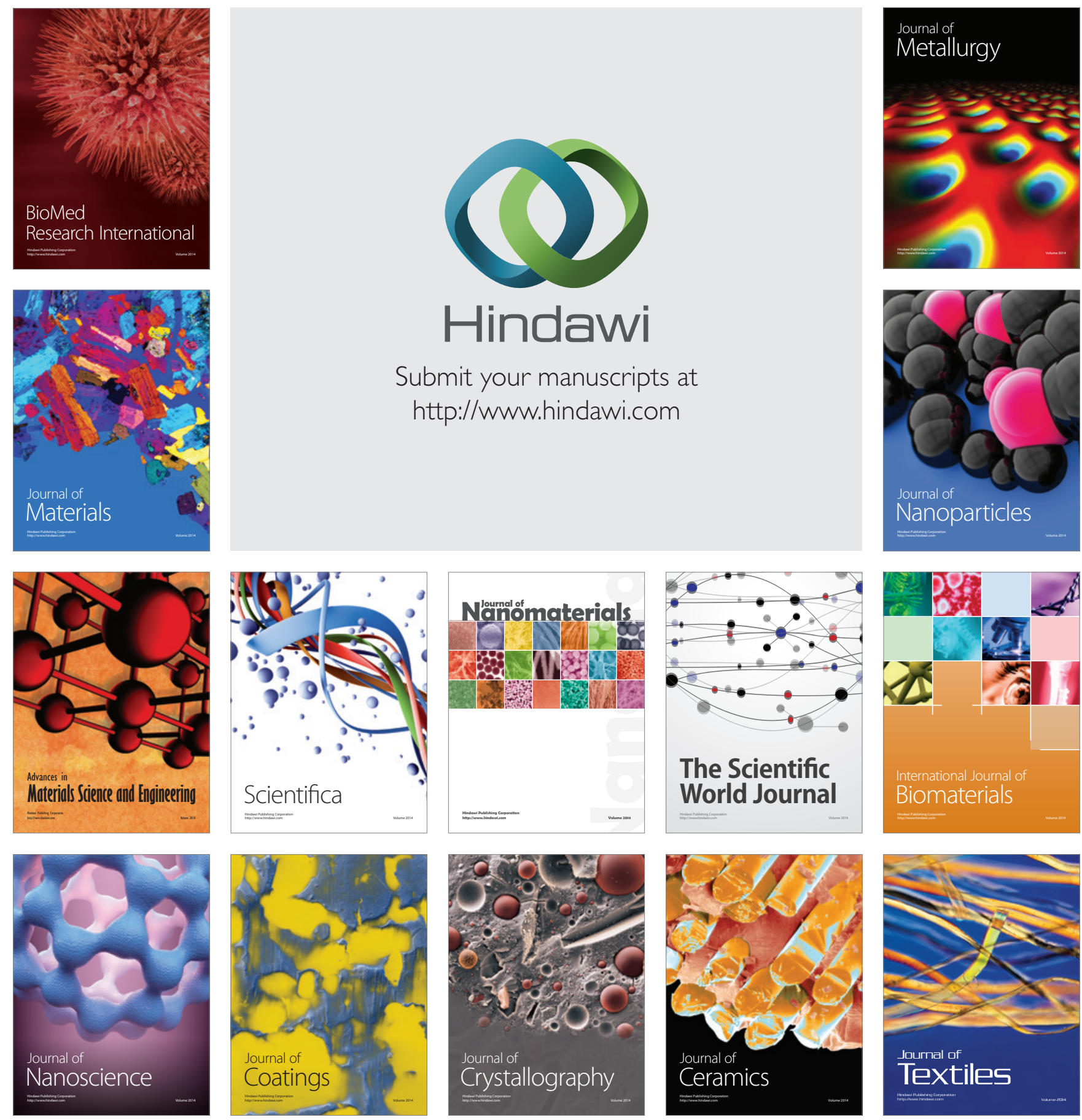